\title{
Tandem Ring-Opening-Ring-Closing Metathesis for Functional Metathesis Catalysts
}

\author{
Amit A. Nagarkar, Mohammad Yasir, Aurelien Crochet, Katharina M. Fromm, and \\ Andreas F. M. Kilbinger*
}

\begin{abstract}
Use of a tandem ring-opening-ring-closing metathesis (RORCM) strategy for the synthesis of functional metathesis catalysts is reported. Ring opening of 7-substituted norbornenes and subsequent ring-closing metathesis forming a thermodynamically stable 6-membered ring lead to a very efficient synthesis of new catalysts from commercially available Grubbs' catalysts. Hydroxy functionalized Grubbs' firstas well as third-generation catalysts have been synthesized. Mechanistic studies have been performed to elucidate the order of attack of the olefinic bonds. This strategy was also used to synthesize the ruthenium methylidene complex.
\end{abstract}

$M$ etathesis is a process in which a metal carbene can be used to construct new carbon-carbon double bonds. ${ }^{[1]}$ It has been widely used as well as extensively reviewed. ${ }^{[2]}$ Historically, metathesis chemistry started with ill-defined catalysts, ${ }^{[3,4]}$ but the development of well-defined metathesis catalysts provided an impetus to extensive applications in synthetic organic and polymer chemistry. There are mainly two metals used in metathesis catalysts: molybdenum-based complexes developed by the Schrock group, and rutheniumbased metathesis catalysts developed by the Grubbs group. ${ }^{[5]}$ Although newer molybdenum-based metathesis catalysts are much more tolerant towards water and oxygen, ${ }^{[6,7]}$ commercially available ruthenium-based metathesis catalysts are the catalysts of choice for many polymer chemists. ${ }^{[8]}$

The first generation and the third generation of Grubbs' metathesis catalysts (Figure 1; G1 and G3) are the most common catalysts used for polymer synthesis owing to their favorable initiation/propagation rate ratio, which makes them suitable for living polymerizations. However because of their remarkable tolerance towards various functional groups, functional termination of a polymerization reaction is not straightforward. Ethyl vinyl ether is the most commonly used terminating agent, but it transfers only a non-functional methylene unit onto the polymer chain end. Substituted vinyl ethers, ${ }^{[9-12]}$ acrylates, ${ }^{[13,14]}$ vinyl carbonates and lactones, ${ }^{[15]}$ protected amines, ${ }^{[16]}$ unsaturated acetals, ${ }^{[17]}$ metathesis with acyclic olefins, ${ }^{[18]}$ and cyclic olefins ${ }^{[19]}$ have been used to

[*] Dr. A. A. Nagarkar, M. Yasir, Dr. A. Crochet, Prof. Dr. K. M. Fromm, Prof. Dr. A. F. M. Kilbinger

Department of Chemistry, University of Fribourg

Chemin du Musee 9, 1700 Fribourg (Switzerland)

E-mail: andreas.kilbinger@unifr.ch

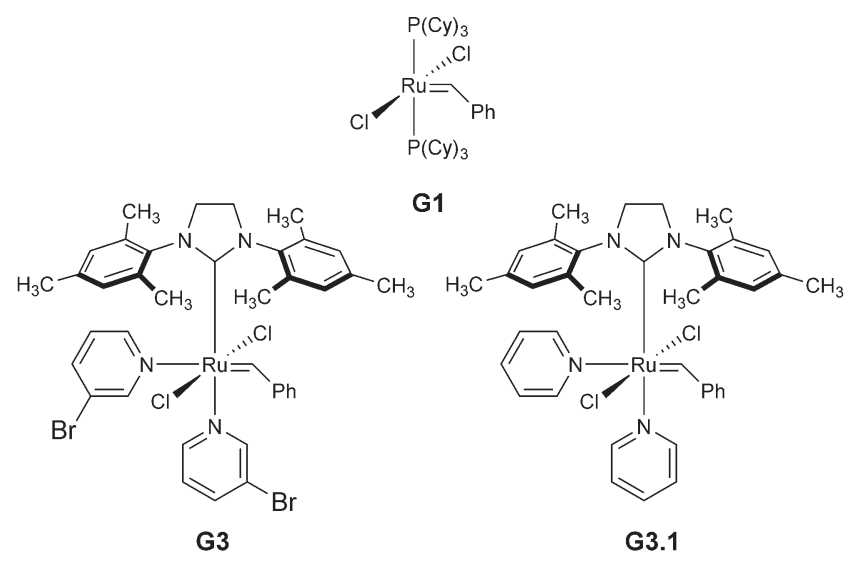

Figure 1. Two commercially available metathesis catalysts. First-generation (G1) and third-generation (G3) Grubbs catalyst. The thirdgeneration pyridine complex (G3.1) was prepared from G3 by addition of excess pyridine.

terminate ring-opening metathesis polymerization (ROMP) reactions. Such a functional termination can only ever give a mono-telechelic polymer, that is, a polymer carrying a desired functional group on one chain end.

Homotelechelic polymers, that is, polymers carrying the same functional group at both the chain ends, have also been reported by the Grubbs' group ${ }^{[20]}$ as well as our group. ${ }^{[21]}$ Heterotelechelic polymers are more challenging to synthesize and there are relatively few reports of synthesis of heterotelechelic polymers by ROMP. Heterotelechelic ROMP polymers were prepared using the sacrificial synthesis strategy. ${ }^{[22]}$ However, this strategy is limited to few functional groups and is not atom-economical.

Another route to the synthesis of heterotelechelic ROMP polymers is using prefunctionalized initiators. ${ }^{[23-26]}$ The initiators already carry a functional group and termination reactions would give a second, possibly different functional group. However, one drawback of this method is the synthesis of a new functional initiator for every desired functional group. Moreover, it involves extensive purification of the initiators and is often low yielding.

One way to synthesize new derivatives of the Grubbs-type ruthenium complexes is a simple metathesis step with excess of a substituted styrene derivative. However, in the case of the first-generation catalyst G1, the equilibrium constants for this reaction are typically not very high. ${ }^{[27]}$ This strategy can work in case of Grubbs' third-generation catalysts (G3). However, in both cases, an excess of the substituted styrene would have 


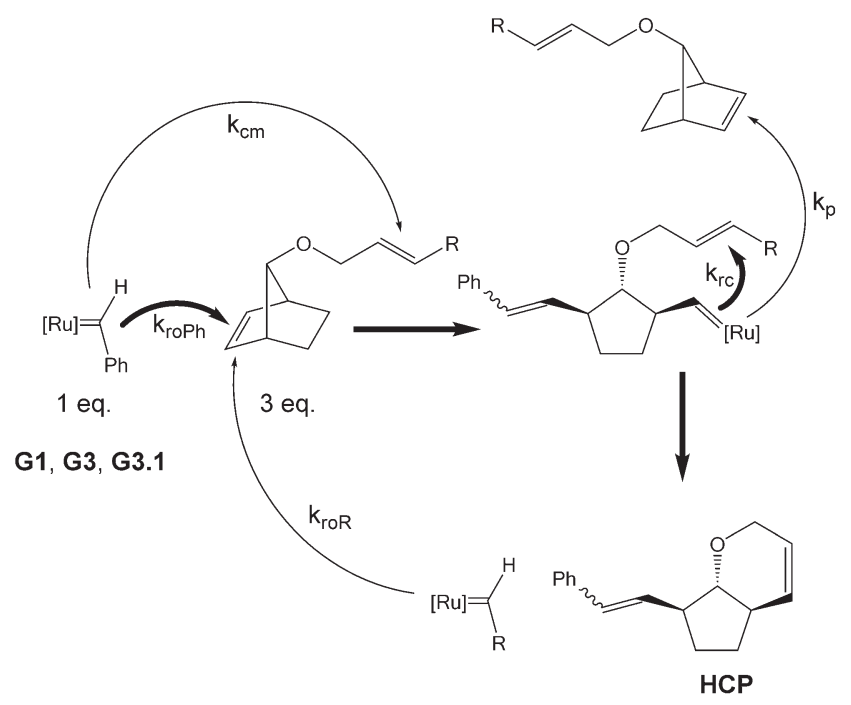

Scheme 1. The generalized idea of using tandem ring-opening-ringclosing metathesis using two olefins of greatly differing reactivity to synthesize new metathesis catalysts. The sequence of metathesis reactions is defined by decreasing olefin reactivity. Bold arrows: desired reaction pathways/higher reaction rates expected. Normal arrows: side reactions/slower reaction rates.

to be added, which would need to be removed before carrying out polymerization reactions.

To synthesize a prefunctionalized Grubbs-type ruthenium carbene initiator for ring-opening metathesis polymerization without the need of any purification step, we devised a process based on tandem ring-opening-ring-closing metathesis (RORCM) using a substrate carrying two double bonds of greatly differing reactivity (Scheme 1$).^{[28]}$

We hypothesized that the Grubbs benzylidene complex would ring open the strained norbornene double bond faster than undergoing cross-metathesis with the allylic ether $\left(k_{\mathrm{roPh}} \gg\right.$ $\left.k_{\mathrm{cm}}\right)$. The newly formed ruthenium carbene would then ideally undergo intramolecular ring-closing metathesis faster than intermolecular reaction with another norbornene $\left(k_{\mathrm{rc}}>k_{\mathrm{p}}, \mathrm{p}=\right.$ propagation). This would yield a hexahydrocyclopenta $[b]$ pyran derivative (HCP) and a newly functionalized ( $\mathrm{R}$ group) ruthenium-carbene complex. If we further assume that the rate of ring-opening metathesis of the new carbene complex with norbornene is slower than that of the ruthenium benzylidene complex $\left(k_{\mathrm{roR}}<k_{\mathrm{roPh}}\right)$, the reaction should be irreversibly driven towards the formation of the new carbene complex. As the norbornene derivative was used in an excess (3 equiv), two equivalents would remain after all ruthenium benzylidene complex had reacted. These two equivalents would then react in a tandem ring opening-ring closing sequence with the newly formed carbene complex, thereby regenerating the identical ruthenium carbene while consuming all excess of norbornene. In the end, the reaction mixture should therefore only contain the newly formed ruthenium carbene complex and HCP derivatives, which should exhibit low metathesis reactivity because of the lack of ring strain. A subsequent polymerization reaction could simply be carried out by adding a strained monomer to the same reaction vessel without the need of intermediate purification.
Tandem ring-opening-ring-closing metathesis has been used many times and provides access to many complex organic structures. ${ }^{[29-31]}$ Most recently, the Choi group investigated ring-opening-ring-closing-cross-metathesis reactions. ${ }^{[32,33]}$ However, there are no reports of new catalyst syntheses using such a method.

To test the RORCM hypothesis outlined in Scheme 1, compounds 1-7 were synthesized (see the Supporting Information). When 7-syn-substituted norbornene (1) was added to a solution of $\mathbf{G 1}$, no reaction could be observed by ${ }^{1} \mathrm{H}$ NMR spectroscopy (see the Supporting Information). A diminished reactivity of $s y n$-substituted norbornene derivatives has already been reported. ${ }^{[34]}$ Therefore, anti-substituted compound 2 was synthesized to circumvent the steric problems observed in $\mathbf{1}$. The reaction of $\mathbf{2}$ with $\mathbf{G 1}$ was followed by ${ }^{1} \mathrm{H}$ NMR spectroscopy. The formation of the expected 4methoxybenzylidene complex was observed; however, the reaction proceeded at a very slow rate with only $28 \%$ formation of the new complex after $20 \mathrm{~h}$ of reaction time (see the Supporting Information).

Acrylates have been used successfully in metathesis reactions, ${ }^{[14]}$ but they are relatively poor substrates owing to their electron-deficient double bond. To increase the rate of the reaction, the electron deficient cinnamate group was replaced with allyl ether derivatives (3-7).

The reaction of 3 equiv of either 3-7 with G1 (or 4 with G3.1) gave the new respective carbene complexes in excellent yields apart from compound $\mathbf{6}$, which yielded an alkylidene rather than a benzylidene (see the Supporting Information). The RORCM method described herein provides a very fast synthesis of a prefunctionalized metathesis catalyst and no purification step is required.

A special case of a ruthenium alkylidene complex is the methylidene complex $\mathbf{G 1}=\mathrm{CH}_{2}$, which has previously been observed and isolated. ${ }^{[35-38]}$ However, its synthesis often requires metathesis with ethylene gas at high pressures. To investigate whether RORCM could yield the methylidene complex, the 7-anti allyl-substituted norbornene 7 (Figure 2) was synthesized and reacted with G1 (Figure 3f). Upon addition of 3 equiv of $\mathbf{7}$ to $\mathbf{G 1}$, the ruthenium methylidene G1 $=\mathrm{CH}_{2}$ was observed within $8 \mathrm{~h}$ in $94 \%$ yield at 18.95 ppm. ${ }^{[35]}$

As a proof of principle towards a heterotelechelic polymer, G1 was reacted to give $\mathbf{G 1 O H}$ as reported above and then monomer exo- $N$-methylnorbornene imide (MNI) was added. Upon quenching with ethyl vinyl ether, a monofunctional ROMP polymer was expected with the phenol at one end and a methylene group at the other. However, to our surprise, the polymer carried the cyclohexene (HCP) end group, which is the product of metathesis with the byproduct of RORCM (Scheme 2). The unsaturated six-membered ring is not inert towards metathesis. ${ }^{[39]}$ Unfortunately, as the sixmembered ring reacts with the living polymer chain end, a simple terminal cross-metathesis cannot be carried out.

The same was true for initiation with G3.1-OH. HCP could also be used as a reversible chain transfer agent in a catalytic living ROMP. These results will be reported elsewhere. 


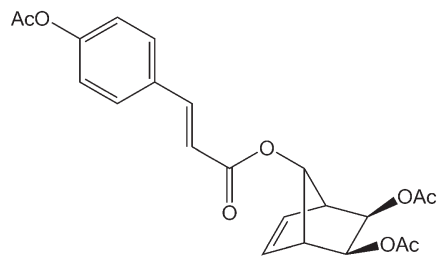

1

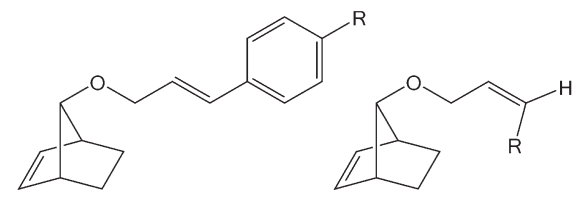

$$
\begin{aligned}
& \mathrm{R}=\mathrm{OCH}_{3} \quad 3 \\
& =\mathrm{OH} \quad 4 \\
& \text { = OTIPS } 4.1 \\
& \begin{array}{ll}
=\mathrm{Br} & 5
\end{array}
\end{aligned}
$$

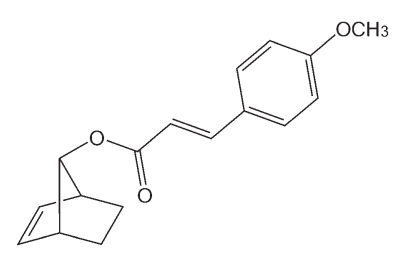

\section{6}

Figure 2. Ring-opening-ring-closing metathesis (RORCM) substrates 1-7 investigated in this study.

Following a similar procedure as reported previously by our group, ${ }^{[21]}$ a mixture of monomer MNI (17 equiv) and MDHP (20 equiv; this is known to give an aldehyde end group) ${ }^{[17]}$ was added to G1-OH. Analysis by MALDI-ToF mass spectrometry showed the exclusive formation of the heterotelechelic polymer carrying a phenolic alcohol at one chain end and an aldehyde at the other (see the Supporting Information). The degree of end functionalization was confirmed by ${ }^{1} \mathrm{H}$ NMR spectroscopy and the polydispersity index of 1.20 supported a living polymerization mechanism. A heterotelechelic polymer with a TIPS and an aldehyde end group was also synthesized using this method (see the Supporting Information). This heterotelechelic polymer was further functionalized with 2,4-dinitrophenylhydrazine, and a very high degree of functionalization was observed.

In conclusion, we have successfully developed a new onepot strategy for the synthesis of functionalized first generation and third generation Grubbs' type metathesis initiators. The methoxy (G1-OMe), phenol (G1-OH and G3.1-OH), bromo (G1-Br), n-butyl (G1- $n \mathrm{Bu})$ and triisopropylsilyloxy (G1-

Figure 3. ' $\mathrm{H}$ NMR spectra $\left(\mathrm{CD}_{2} \mathrm{Cl}_{2}, 300 \mathrm{MHz}\right)$ of the reactions of 3-7 with carbene complexes $\mathrm{Gl}$ or G3.1. a) Reaction of $\mathrm{Gl}$ with 3 equiv of 3 forming G1-OMe (19.48 ppm) within 15 min. (95\% conversion). NMR traces are shifted progressively to the left by $0.2 \mathrm{ppm}$ with increasing time for clarity. b) Reaction of $\mathrm{Gl}$ with 3 equiv of $\mathbf{4}$ forming G1-OH (19.39 ppm) within 20 min. (96\% conversion). Top NMR trace is shifted to the left by $0.2 \mathrm{ppm}$ for clarity. c) Reaction of G3.1 (formed by adding 50 equiv of pyridine to G3) with 3 equiv of 4 forming G3.1$\mathrm{OH}(18.39 \mathrm{ppm})$ within $10 \mathrm{~min}$. (98\% conversion). Top NMR trace is shifted to the left by $0.2 \mathrm{ppm}$ for clarity. d) Reaction of $\mathrm{G} 1$ with 3 equiv. of 5 forming $\mathrm{Cl}-\mathrm{Br}$ (19.98 ppm) within $10 \mathrm{~min}$. (94\% conversion, the residual G1 benzylidene signal is visible to the left of the newly formed $\mathrm{G1}-\mathrm{Br}$ carbene). Top NMR trace is shifted to the left by $0.2 \mathrm{ppm}$ for clarity. e) Reaction of $\mathrm{Gl}$ with 3 equiv. of 6 forming $\mathrm{Gl}=\mathrm{CH}-\mathrm{C}_{3} \mathrm{H}_{7}$ (19.27 ppm) within $2 \mathrm{~h}$ (59\% conversion). NMR traces are shifted to the left by $0.1 \mathrm{ppm}$ for clarity. $\mathrm{f}$ ) Reaction of $\mathrm{G} 1$ with 3 equiv. of 7 forming $\mathrm{Gl}=\mathrm{CH}_{2}$ (18.95 ppm) after $8 \mathrm{~h}$ (94\% conversion). Top NMR trace is shifted to the left by $0.2 \mathrm{ppm}$ for clarity.
OTIPS) catalysts were successfully synthesized in excellent yields. The ease of pre/post-functionalization of the phenolic $\mathrm{OH}$ group opens access to a multitude of functionalized metathesis catalysts. This atom-economical approach requiring only 3 equivalents of the functionalized norbornene provides an easy and efficient access to heterotelechelic polymers as well as polymeric conjugates. As a proof of principle, heterotelechelic polymers were prepared in a onepot strategy. The tandem ring opening ring closing metathesis sequence, which has been used previously for synthesis of
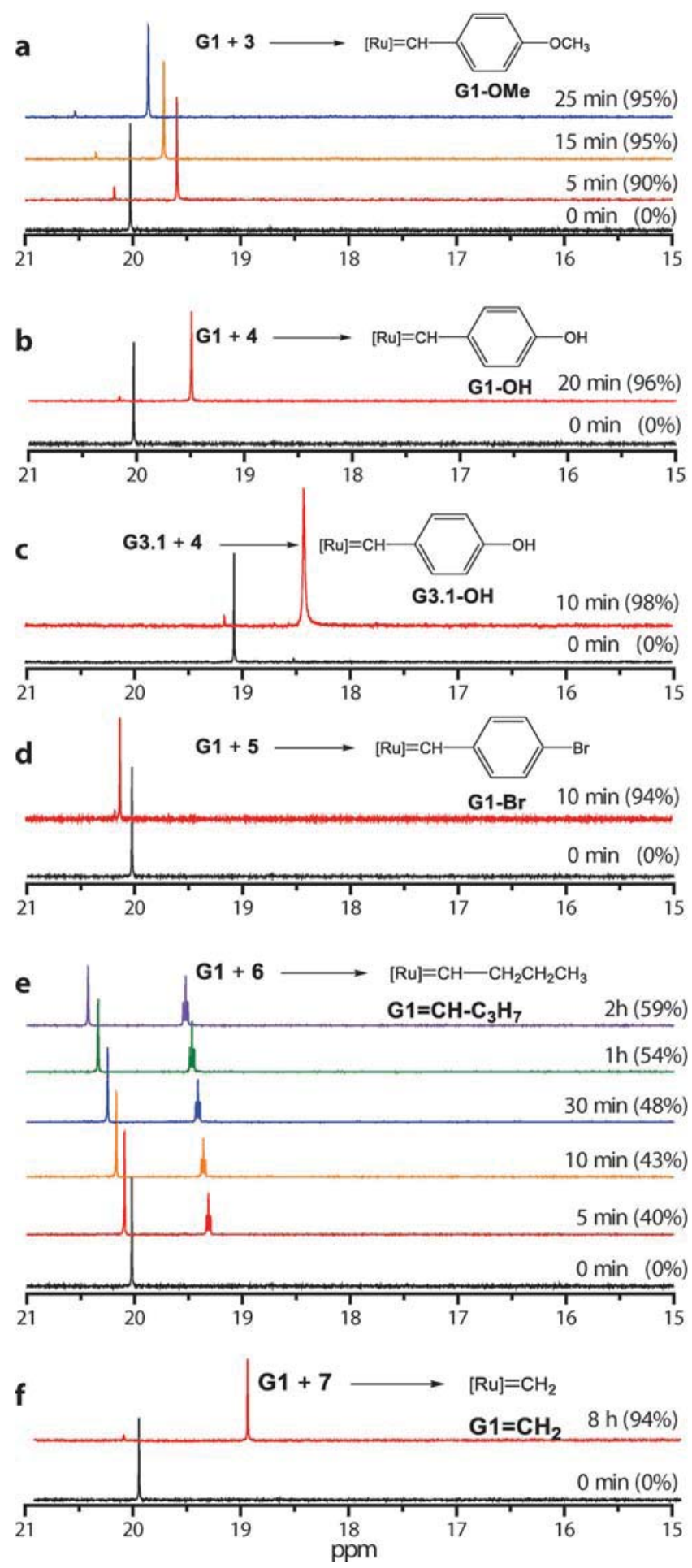

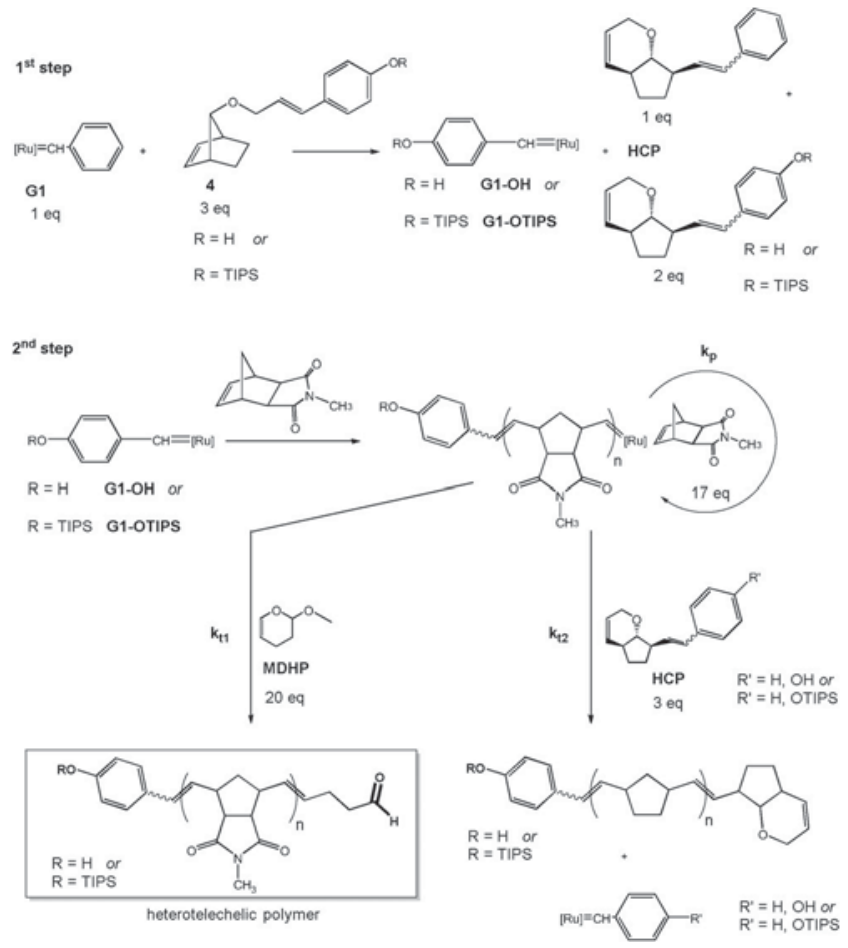

Scheme 2. Synthesis of the heterotelechelic polymer by addition of a mixture of monomer and terminating agent to the reaction vessel containing G1-OH or G1-OTIPS.

complex organic and polymeric compounds, was never investigated from the perspective of catalyst synthesis and modification. This route provides a new and efficient synthetic approach towards derivatives of the Grubbs-type ruthenium carbene complexes. Furthermore, the order of attack of the double bonds in the tandem RORCM was investigated, thereby providing a straightforward route to the ruthenium methylidene complex $\left(\mathbf{G 1}=\mathrm{CH}_{2}\right)$, avoiding the use of ethylene gas and high pressure.

\section{Acknowledgements}

A.A.N., M.Y. and A.F.M.K. thank the Swiss National Science Foundation (SNF) for funding. A.C., K.M.F., and A.F.M.K. thank the Fribourg Center for Nanomaterials (FriMat) for financial support.

Keywords: Grubbs catalysts - heterotelechelic polymers . olefin metathesis · polymerization · ruthenium

How to cite: Angew. Chem. Int. Ed. 2016, 55, 12343-12346 Angew. Chem. 2016, 128, 12531-12534

[1] N. Calderon, Acc. Chem. Res. 1972, 5, 127-132.

[2] Handbook of Metathesis (Ed.: R. H.Grubbs), Wiley-VCH, Weinheim, 2003, chap. 1.3, pp. 8-32.

[3] F. Quignard, C. Larroche, M. Leconte, J.-M. Basset in Mechanistic aspects of the olefin mechanism reaction (Ed.: P.S. Braterman), Plenum Press, New York, 1983.

[4] K. J. Ivin, J. C. Mol, Olefin Metathesis and Metathesis Polymerization, Academic Press, New York, 1997.
[5] S. Kress, S. Blechert, Chem. Soc. Rev. 2012, 41, 4389-4408.

[6] M. R. Buchmeiser, S. Sen, J. Unold, W. Frey, Angew. Chem. Int. Ed. 2014, 53, 9384-9388; Angew. Chem. 2014, 126, 9538-9542.

[7] R. R. Schrock, Chem. Rev. 2009, 109, 3211-3226.

[8] C. W. Bielawski, R. H. Grubbs, Prog. Polym. Sci. 2007, 32, 1-29.

[9] H. Katayama, Y. Fukuse, Y. Nobuto, K. Akamatsu, F. Ozawa, Macromolecules 2003, 36, 7020-7026.

[10] R. M. Owen, J. E. Gestwicki, T. Young, L. L. Kiessling, Org. Lett. 2002, 4, 2293-2296.

[11] E. M. Kolonko, L. L. Kiessling, J. Am. Chem. Soc. 2008, 130, $5626-5627$.

[12] J. E. Gestwicki, C. W. Cairo, D. A. Mann, R. M. Owen, L. L. Kiessling, Anal. Biochem. 2002, 305, 149.

[13] A. Rybak, P. A. Fokou, M. A. R. Meier, Eur. J. Lipid Sci. Technol. 2008, 110, 797-804.

[14] C. Lexer, R. Saf, C. Slugovc, J. Polym. Sci. Part A 2009, 47, 299305.

[15] S. Hilf, R. H. Grubbs, A. F. M. Kilbinger, J. Am. Chem. Soc. 2008, 130, 11040-11048.

[16] A. A. Nagarkar, A. Crochet, K. Fromm, A. F. M. Kilbinger, Macromolecules 2012, 45, 4447.

[17] A. A. Nagarkar, A. F. M. Kilbinger, Chem. Sci. 2014, 5, $4687-$ 4692.

[18] J. Matson, R. H. Grubbs, Macromolecules 2010, 43, 213-221.

[19] S. Hilf, A. F. M. Kilbinger, Nat. Chem. 2009, 1, 537-546.

[20] C. W. Bielawski, D. Benitez, T. Morita, R. H. Grubbs, Macromolecules 2001, 34, 8610-8618.

[21] N. Hanik, A. F. M. Kilbinger, J. Polym. Sci. Part A 2013, 51, 4183.

[22] S. Hilf, A. F. M. Kilbinger, Macromolecules 2010, 43, 208-212.

[23] D. Burtscher, R. Saf, C. Slugovc, J. Polym. Sci. Part A 2006, 44, $6136-6145$

[24] H. Katayama, H. Urushima, F. Ozawa, J. Organomet. Chem. 2000, 606, 16-25.

[25] C. W. Bielawski, J. Louie, R. H. Grubbs, J. Am. Chem. Soc. 2000, $122,12872-12873$

[26] A. V. Ambade, S. K. Yang, M. Weck, Angew. Chem. Int. Ed. 2009, 48, 2894-2898; Angew. Chem. 2009, 121, 2938-2942.

[27] D. R. Lane, C. M. Beavers, M. M. Olmstead, N. E. Schore, Organometallics 2009, 28, 6789-6797.

[28] W. J. Zuercher, M. Hashimoto, R. H. Grubbs, J. Am. Chem. Soc. 1996, 118, 6634-6640.

[29] H. Park, H.-K. Lee, T.-L. Choi, J. Am. Chem. Soc. 2013, 135, $10769-10775$

[30] G. S. Weatherhead, J. G. Ford, E. J. Alexanian, R. R. Schrock, A. H. Hoveyda, J. Am. Chem. Soc. 2000, 122, 1828-1829.

[31] D. S. La, J. G. Ford, E. S. Sattely, P. J. Bonitatebus, R. R. Schrock, A. H. Hoveyda, J. Am. Chem. Soc. 1999, 121, 11603-11604.

[32] H.-K. Lee, K.-T. Bang, A. Hess, R. H. Grubbs, T.-L. Choi, J. Am. Chem. Soc. 2015, 137, $9262-9265$.

[33] H. Park, E.-H. Kang, L. Müller, T.-L. Choi, J. Am. Chem. Soc. 2016, 138, 2244-2251.

[34] J. Holtsclaw, M. Koreeda, Org. Lett. 2004, 6, 3719-3722.

[35] P. Schwab, R. H. Grubbs, J. W. Ziller, J. Am. Chem. Soc. 1996, $118,100-110$.

[36] C. Pietraszuk, H. Fischer, S. Rogalski, B. Marciniec, J. Organomet. Chem. 2005, 690, 5912-5921.

[37] C. Pietraszuk, B. Marciniec, H. Fischer, Organometallics 2000, $19,913-917$

[38] J. A. M. Lummiss, F. A. Perras, R. McDonald, D. L. Bryce, D. E. Fogg, Organometallics 2016, 35, 691-698.

[39] A. A. Nagarkar, A. F. M. Kilbinger, Nat. Chem. 2015, 7, $718-$ 723. 